\title{
Evaluation of Serum Zinc Concentration in Patients with Tuberculous Lymphadenitis
}

\author{
Dr. Md. Rashadul Kabir ${ }^{*}$, Dr. Mohammad Farhad ${ }^{2}$, Dr. Md. Ahsan Habib ${ }^{3}$, Dr. Shamshad B. Quraishi ${ }^{4}$, Dr. Mohammad
} Tanvir Islam 5

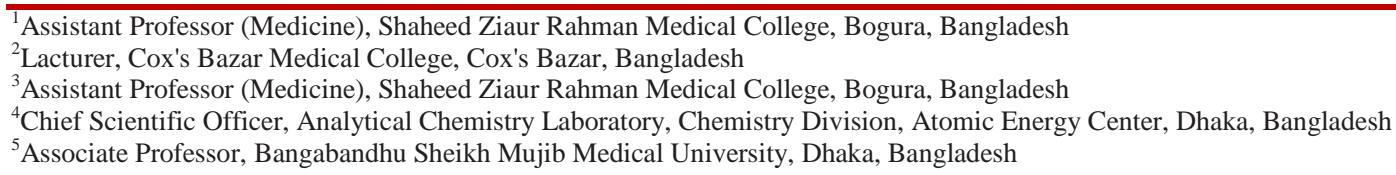

DOI: $10.36347 /$ sjams.2021.v09i01.018

| Received: 20.10.2020 | Accepted: 04.11.2020 | Published: 19.01.2021

*Corresponding author: Dr. Md. Rashadul Kabir

Abstract

Original Research Article

Background: Tuberculosis which is a severe bacterial infection caused by Mycobacterium tuberculosis, compromises the immune system. Inadequate intake of micronutrients alters the immune response of the host predisposing to infection. Zinc plays vital role in the immune status. So serum zinc concentration in patients with tuberculous lymphadenitis is a very potential thing in treating the respective patients. Aim of the study: The aim of this study was to evaluate the serum zinc concentrations in patients with tuberculous lymphadenitis. Methods: The study was conducted in the Department of Internal Medicine of Bangabandhu Sheikh Mujib Medical University (BSMMU), Dhaka, during the period from January 2016 to March 2017. The study included 25 freshly diagnosed tuberculous lymphadenitis patients as case and 25 tuberculosis negative normal healthy subjects as control as per inclusion and exclusion criteria. Serum zinc concentrations were estimated by using atomic absorption spectrophotometry before initiating antituberculosis chemotherapy. Result: In analyzing serum zinc level of the study patients, it was observed that, $17(68.0 \%)$ patients had $<70 \mu \mathrm{g} / \mathrm{dl}$ (low) in Case Group and $10(40.0 \%)$ in Control Group. The mean serum zinc was $66.3 \pm 14.2 \mu \mathrm{g} / \mathrm{dl}$ in Case Group and 74.9.0 $\pm 13.8 \mu \mathrm{g} / \mathrm{dl}$ in Control Group. The difference was statistically significant $(\mathrm{p}<0.05)$ between two Groups. Conclusion: This study indicates that tuberculous lymphadenitis patients have lower level of serum zinc concentrations. This demands the need for further investigations so that strategies for zinc supplementation can be planned in monitoring responses to antituberculous chemotherapy in addition to its potential as diagnostic parameter.

Keywords: Tuberculosis, Micronutrient, Zinc, Chemotherapy.

Copyright $\odot 2021$ The Author(s): This is an open-access article distributed under the terms of the Creative Commons Attribution 4.0 International License (CC BY-NC 4.0) which permits unrestricted use, distribution, and reproduction in any medium for non-commercial use provided the original author and source are credited.

\section{INTRODUCTION}

Tuberculosis is a global disease and the second leading cause of death from an infectious disease worldwide. In 2015 an estimated 10.4 million new cases occurred globally and 1.4 million people died of TB. Bangladesh is the sixth highest TB-burden country in the world [1]. Despite effective treatment regimen for tuberculosis (TB), it remains a major source of morbidity and mortality throughout the world in developing countries, including Bangladesh. In Bangladesh, the prevalence of reported active TB in 2015 was 362 (Range: 234-517) per 100,000 population with a mortality of 45(range: 27-68) per 100,000 population (WHO 2015). TB-lymphadenitis is the most common comprises 68\% [2] of all extra-pulmonary tuberculosis patients. The association between poverty and TB is well-recognized, and the highest rates of TB were found in the poorest section of the community [3]. TB occurs more frequently among low-income people living in overcrowded areas and persons with little schooling [4]. Poverty may result in poor nutrition which may be associated with alterations in immune function (WHO int. publications). Nutritional status is one of the most important determinants of resistance to infection, and it is well-established that nutritional deficiency is associated with impaired immune functions ${ }^{5}$. Undernutrition increases the risk of tuberculosis and in turn tuberculosis can lead to malnutrition. Undernutrition is therefore highly prevalent among people with tuberculosis. It has been demonstrated that undernutrition is a risk factor for progression from tuberculosis infection to active tuberculosis disease and that undernutrition at the time of diagnosis of active tuberculosis is a predictor of 
increased risk of death and tuberculosis relapse. However, the evidence concerning the effect of nutritional supplementation on tuberculosis prevention and health outcomes among people with tuberculosis had not previously been systematically reviewed (WHO int. nutrition). Recent reviews have shown that deficiency in the micronutrients and trace elements may have adverse effects on the immune status [5] and micronutrient supplementation can lead to boosting of the immune system, which may help improve the response to TB treatment. A great deal of research supports the fact that the impairment of the immune system due to trace element deficiency can be sufficient to increase the risk of mortality and morbidity due to infections. It is also stated that the supplementation of trace elements restores immune competence [6]. Zinc $(\mathrm{Zn})$ is referred to as a trace element. It plays a vital role over immune system in various ways. Both innate and acquired immunity are impaired by zinc deficiency. Deficiency affects host defense by reducing the number of circulating $\mathrm{T}$ cells and phagocytosis activity of other cells which ultimately impair cell mediated immunity. The cell-mediated immunity plays a major role in the causation of tuberculosis. The low concentrations of serum zinc in tuberculous lymphadenitis patients may be from preexisting deficiencies due to nutritional deficiency that enhanced susceptibility to infection, and/or for consumption of serum zinc in TB lymphadenitis due to redistribution. A case control study from Indonesia reported that the prevalence of low serum zinc concentrations among pulmonary tuberculosis (PTB) patients and control subjects were $21 \%$ and 5\% respectively [7]. Ghulam and co-authors from Pakistan found significantly low serum zinc levels in PTB patients compared to controls [8]. A systematic review of relevant epidemiological research involved meta-analysis from 11 intervention trials revealed that the global risk of zinc deficiency was estimated at $31 \%$, ranging from $4-73 \%$ across WHO sub-regions. Research conducted recently suggests that prevalence of zinc deficiency in developing countries is very common and $61 \%$ of the population is at increased risk of low dietary zinc intake [9]. Studies demonstrated that $49.4 \%$ of adolescent girls in Delhi [10] and 52\% non-pregnant women of central India suffered from zinc deficiency [11]. There is a lack of literature to reflect zinc deficiency in Bangladesh. Malnutrition and poverty in Bangladesh are the leading cause of high rate of zinc deficiency, especially in early pregnancies [12]. Randomized trial reports have shown that vitamin A and micronutrient supplementation resulted in improved prognosis in pulmonary tuberculosis. Since there are a lot of studies reporting malnutrition and beneficial effects of micronutrient supplementation but very few studies on the deficiency status of these micronutrients per se in tuberculosis patients, the present study was carried out to compare the plasma level of zinc in tuberculous lymphadenitis. The aim of this study was to evaluate the serum zinc concentrations in patients with tuberculous lymphadenitis.

\section{OBJECTIVE}

The general objective of this study was to evaluate the serum zinc concentrations in patients with tuberculous lymphadenitis.

\section{Methodology \& Materials}

The study was conducted in the Department of Internal Medicine of Bangabandhu Sheikh Mujib Medical University (BSMMU), Dhaka, during the period from January 2016 to March 2017. The study included 25 freshly diagnosed tuberculous lymphadenitis patients as case and 25 tuberculosis negative normal healthy subjects as control as per inclusion and exclusion criteria. Data were collected by using pre-designed data sheet prepared for the study with face to face interview, relevant clinical examinations and investigations. The data sheet was pre-tested and face validated by consulting with experts. According to the inclusion criteria patients with newly diagnosed Tuberculous lymphadenitis, and patients of any gender aged between 15-60 years were included in the study. On the other hand, according to the exclusion criteria of this study, patients already on antituberculous therapy, disseminated tuberculosis, diabetic, women with pregnancy or taking oral contraceptives, patients with chronic liver disease or renal failure, cases with myocardial infarction, carcinoma or nephritic syndrome and/or zinc receiving patients were excluded from this study. Patients with FNAC or Biopsy proven newly diagnosed untreated tuberculous lymphadenitis patients were selected as cases. For collecting of patients I used to go to OPD of internal Medicine and ENT and also to DOTS (directly observed treatment, short course) Centre, BSMMU. I also used to search newly diagnosed patients with tubercular lymphadenitis admitted in IPD, internal Medicine, BSMMU. I requested my colleagues to inform me or to send the patient with newly diagnosed tuberculous lymphadenitis to me at an allocated place and time if they found in OPD or admitted in IPD. At first Study purpose was explained to the patient and informed written consent was taken, then history was taken and examination was performed to exclude contributory and co-morbid conditions that may alter the serum zinc concentration. BMI of the patients was calculated; MT was done. CBC, SGPT, S. Creatinine and random blood sugar was done in all cases. Chest-Xray and Ultrasonography of abdomen were done to exclude disseminated tuberculosis or other diagnosis. Age, sex matched healthy control who were fulfill the inclusion and exclusion criteria were collected from patient's attendance, hospital stuff and patients with other diagnosis that did not alter the serum biochemistry from IPD and OPD of BSMMU. Controls were selected on the basis of only history and clinical examination. Three milliliter of Venous blood was collected by a trained technician who has proper knowledge about the procedure and safety of venipuncture. This study has minimum chance of physical risks during three $\mathrm{ml}$ of 
Rashadul Kabir et al; Sch J App Med Sci, Jan, 2021; 9(1): 92-96

blood sample collection. If any complication arises during blood collection that were managed properly. The blood specimens for zinc assay was collected in zinc-free tubes supplied from Atomic Energy Centre, Dhaka. Venous blood specimens were placed immediately after collection in a cold box, protected from light exposure and transported on ice packs to Atomic energy center, Dhaka. The serum was separated within six hours of collection and stored at $-20^{\circ} \mathrm{C}$ until processing. Serum zinc levels were measured by atomic absorption spectrophotometry to determine the serum zinc concentration. Investigator will use a code number for each subject and code number was decoded by investigator. Thus confidentiality and anonymity was maintained. As it is an observational and case control study, no experimental drugs was used in this study. About $3 \mathrm{ml}$ venous blood was collected from every cases (prior to initiation of anti-TB treatment) and controls in trace element free tube. These test tubes were made zinc free from Atomic Energy Centre laboratory prior to use. Venous blood specimens were collected by a trained technician. Powder free gloves were used during blood collection. Serum was separated by centrifugation within 2 hour of collection and kept at $-20^{\circ} \mathrm{C}$ until analyzed within 4 days. Concentration of zinc in serum was determined using an atomic absorption spectrophotometry at Analytical chemistry laboratory of Atomic Energy Centre, Dhaka, Bangladesh.

\section{RESULT}

In this study finally 50 subjects were included in this study, 25 were newly diagnosed tuberculous lymphadenitis patients before starting anti tubercular therapy as case and 25 were tuberculosis negative control. In analyzing age and gender of the total participants, it was observed that, more than half $(52.0 \%)$ of the patients belonged to age $\leq 30$ years in Case Group and $15(60.0 \%)$ in Control Group. The mean age was $32.1 \pm 12.0$ years in Case and 30.1 \pm 12.0 years in Control Group. More than half $(52.0 \%)$ patients were female in Case and $14(56.0 \%)$ in Control Group. On the other hand, in local examination of the study patients, it was observed that, more than three fourth $(80.0 \%)$ patients had neck gland. Single $\mathrm{LN}$ had 6 $(24.0 \%)$. The mean length was $3.4 \pm 0.8 \mathrm{~cm}$ with ranged from 2 to $5 \mathrm{~cm}$. Mean wide was $2.8 \pm 0.6 \mathrm{~cm}$ with ranged from 2 to $5 \mathrm{~cm}$. Tenderness had $3(12.0 \%)$. Twenty three $(92.0 \%)$ patients had firm. Smooth surface had 15 $(60.0 \%)$, relation with surrounding structures 19 (76.0\%) patients had mobile. Almost three fourth $(72.0 \%)$ patients had matted nature. In analyzing serum zinc level of the study patients, it was observed that, 17 (68.0\%) patients had $<70 \mu \mathrm{g} / \mathrm{dl}$ (low) in Case Group and $10(40.0 \%)$ in Control Group. The mean serum zinc was $66.3 \pm 14.2 \mu \mathrm{g} / \mathrm{dl}$ in Case Group and 74.9.0 \pm 13.8 $\mu \mathrm{g} / \mathrm{dl}$ in Control Group. The difference was statistically significant $(\mathrm{p}<0.05)$ between two groups.
Table-1: Age and gender distribution of participants $(\mathrm{N}=\mathbf{5 0})$

\begin{tabular}{|l|l|l|l|l|}
\hline \multirow{2}{*}{ Particulars } & \multicolumn{2}{|l|}{ Case (n=25) } & \multicolumn{2}{l|}{ Control (n=25) } \\
\cline { 2 - 5 } & $\mathbf{n}$ & $\mathbf{\%}$ & $\mathbf{n}$ & $\mathbf{\%}$ \\
\hline Age (Years) & 13 & 52 & 15 & 60 \\
\hline$\leq 30$ & 5 & 20 & 5 & 20 \\
\hline $31-40$ & 5 & 20 & 3 & 12 \\
\hline $41-50$ & 2 & 8 & 2 & 8 \\
\hline$>50$ & $32.1 \pm 12.0$ & $30.1 \pm 12.0$ \\
\hline Mean \pm SD & 17,60 & 17,61 \\
\hline Range (min, max) & \multicolumn{5}{|l}{} \\
\hline Gender & 12 & 48 & 11 & 44 \\
\hline Male & 13 & 52 & 14 & 56 \\
\hline Female
\end{tabular}

Table-2: Distribution of cases by examination of Lymphnodes ( $\mathbf{n}=\mathbf{2 5})$

\begin{tabular}{|c|c|c|}
\hline Particulars & $\mathbf{n}$ & $\%$ \\
\hline \multicolumn{3}{|l|}{ Site } \\
\hline Neck gland & 20 & 80 \\
\hline Unilateral & 15 & 75 \\
\hline Bilateral & 5 & 25 \\
\hline Axillary & 3 & 12 \\
\hline Others & 2 & 8 \\
\hline \multicolumn{3}{|c|}{ Number of LN } \\
\hline Single & 6 & 24 \\
\hline Multiple & 19 & 76 \\
\hline Tenderness & 3 & 12 \\
\hline \multicolumn{3}{|l|}{ Consistency } \\
\hline Soft & 1 & 4 \\
\hline Firm & 23 & 92 \\
\hline Hard & 1 & 4 \\
\hline \multicolumn{3}{|l|}{ Surface } \\
\hline Irregular & 10 & 40 \\
\hline Smooth & 15 & 60 \\
\hline \multicolumn{3}{|l|}{ Type } \\
\hline Mobile & 19 & 76 \\
\hline Fixed & 6 & 24 \\
\hline \multicolumn{3}{|l|}{ Nature } \\
\hline Matted & 18 & 72 \\
\hline Discrete & 7 & 28 \\
\hline
\end{tabular}

Table-3: Distribution of the study patients by serum zinc level $(\mathbf{n}=50)$

\begin{tabular}{|l|l|l|l|l|l|}
\hline \multirow{2}{*}{$\begin{array}{l}\text { Serum zinc } \\
(\boldsymbol{\mu g} / \mathbf{d l})\end{array}$} & \multicolumn{2}{|l|}{$\begin{array}{l}\text { Case } \\
(\mathbf{n = 2 5})\end{array}$} & \multicolumn{2}{l|}{$\begin{array}{l}\text { Control } \\
(\mathbf{n = 2 5})\end{array}$} & \multirow{2}{*}{ value } \\
\cline { 2 - 5 } & $\mathbf{n}$ & $\mathbf{\%}$ & $\mathbf{n}$ & $\mathbf{\%}$ & \\
\hline$<70$ (low) & 17 & 68 & 10 & 40 & \\
\hline $\begin{array}{l}70-120 \\
(\text { normal) }\end{array}$ & 8 & 32 & 15 & 60 & \\
\hline$>120$ (high) & 0 & 0 & 0 & 0 & \\
\hline Mean+SD & $66.3 \pm 14.2$ & $74.9 \pm 13.8$ & $0.034^{\text {s }}$ \\
\hline $\begin{array}{l}\text { Range (min, } \\
\text { max) }\end{array}$ & $38.6,102.9$ & \multicolumn{2}{|l|}{$52.5,120$} & \\
\hline
\end{tabular}

$s=$ significant $p$ value reached from unpaired $t$-test 


\section{DISCUSSION}

The aim of this study was to evaluate the serum zinc concentrations in patients with tuberculous lymphadenitis. In this study, we observed a significant amount of low serum zinc concentrations in patients with tuberculous lymphadenitis than tuberculosis negative controls. These observations are in agreement with the reports from in this country [13], India [14], Indonesia [7], Ethiopia [15] and Ecuador [16]. In contrary to the previous studies and the current one [17], from Turkey studied 22 pulmonary TB patients and 18 healthy subjects and found an increase in the levels of serum zinc in PTB but the mechanism of this increase was not explained. In our study, the serum zinc concentrations revealed an inverse relationship with increasing age in both TB lymphadenitis patients and controls and the difference is not significant. This finding validates the observation of a previous study [8]. In this study, the mean serum zinc concentrations differences between male and female were not significant in both TB cases and controls. It is in agreement with a study in Indonesia ${ }^{7}$ and in Ethiopia [15] but inconsistent with a previous study in India where they found $11 \%$ low serum zinc in female than male and in Lisbon, Portugal; where [18] found significantly high serum zinc concentration in male than female. The comparisons between BMI categories and mean serum zinc concentrations were not statistically significant between cases and controls in this study. Association of age, Gender and BMI with serum zinc level in patients with tuberculous lymphadenitis was evaluated in the present study. Any significant association was not observed among them. A study published in $2006^{15}$ observed that there was no significant association between age and serum zinc level in patients of tuberculosis. In another study from Lucknow, India, it was reported that there was no association of age with serum zinc level in patients with tuberculosis [19]. A study in Ethiopia [15] found no association of BMI with serum zinc concentrations in tuberculosis patient. We enrolled a small sample size of 50 subjects. Among them, females were more than males. These data corroborate with a previous study in Ethiopia [15] where more than half $(58 \%)$ of the study subjects were female but incongruent with a recent study in India [20] where more than half $(54.3 \%)$ of the study subjects were male. This finding may be due to convenient sampling design or due to male dominance of the society like Bangladesh, where males are mostly responsible for bread and butter of his family. In this present study the highest numbers of patients were in the young age group. It is congruent with the study done by [20] but incongruent with the study done by Choudhury $\mathrm{N}$ et al., where mean age group was little higher than the current study. In this current study, it was observed that the frequency of low BMI status was more in TB patients than control. The difference were statistically not significant $(p>0.05)$ between two groups. It is consistent with an Indonesian study [7], where they observed low BMI in tuberculosis than control. Most of respondents for both case and control were in normal BMI. These findings are congruent with the observation of a previous study [15]. Investigation profile showed, TB patients observed relatively low hemoglobin with high WBC total count, ESR and MT reaction in this study. These findings are in agreement with the reports from Indonesia ${ }^{7}$ and India [20].

\section{Limitations of the study}

This was a single centered study with a small sized of sample. So the findings of this may not reflect the exact scenario of the whole country.

\section{CONCLUSION AND RECOMMENDATIONS}

For getting more specific findings we would like to recommend for conducting more studies regarding the same issue with larger sized sample.

\section{REFERENCES}

1. Global TB Report, 2016, https://apps.who.int/medicinedocs/en/m/abstract /Js23098en/.

2. Kamal SM, Ahasan HN, Ahmed S, Ayaz KF, Mahbub MS, Khan MA, Gupta RD, Alam MB, Miah MT. Isolation and identification of mycobacterium from extrapulmonary specimen at NTRL, NIDCH. Journal of Medicine. 2010;11(2):128-30.

3. Rundi C. Understanding tuberculosis: perspectives and experiences of the people of Sabah, East Malaysia. Journal of health, population, and nutrition. 2010 Apr;28(2):114-123.

4. Spence DP, Hotchkiss J, Williams CS, Davies PD. Tuberculosis and poverty. British Medical Journal. 1993 Sep 25;307(6907):759-61.

5. Perronne C. Tuberculosis, HIV infection, and malnutrition: an infernal trio in central Africa. Nutrition (Burbank, Los Angeles County, Calif.). 1999 Apr;15(4):321.

6. Mehta JB, Fields CL, Byrd Jr RP, Roy TM. Nutritional status and mortality in respiratory failure caused by tuberculosis. Tennessee medicine: journal of the Tennessee Medical Association. 1996 Oct 1;89(10):369-71.

7. Karyadi E, Schultink W, Nelwan RH, Gross R, Amin Z, Dolmans WM, Van Der Meer JW, Hautvast JG, West CE. Poor micronutrient status of active pulmonary tuberculosis patients in Indonesia. The Journal of nutrition. $2000 \mathrm{Dec}$ 1;130(12):2953-8

8. Ghulam H, Kadri SM, Manzoor A, Waseem Q, Aatif MS, Khan GQ, Manish K. Status of zinc in pulmonary tuberculosis. The Journal of Infection in Developing Countries. 2009 Jun 1;3(05):365-8.

9. Micronutrient Initiative. Zinc and human health: results of recent trials and implications for program interventions and research. IDRC, 
Ottawa, ON, CA; Micronutrient Initiative. 2000; 69.

10. Kapil U, Jain K. Magnitude of zinc deficiency amongst under five children in India. The Indian Journal of Pediatrics. 2011 Sep 1;78(9):1069-72.

11. Menon KC, Skeaff SA, Thomson CD, Gray AR, Ferguson EL, Zodpey S, Saraf A, Das PK, Toteja GS, Pandav CS. Concurrent micronutrient deficiencies are prevalent in nonpregnant rural and tribal women from central India. Nutrition. 2011 Apr 1;27(4):496-502.

12. Ahmed $\mathrm{T}$, Mahfuz $\mathrm{M}$, Ireen $\mathrm{S}$, Ahmed $\mathrm{AS}$, Rahman S, Islam MM, Alam N, Hossain MI, Rahman SM, Ali MM, Choudhury FP. Nutrition of children and women in Bangladesh: trends and directions for the future. Journal of health, population, and nutrition. 2012 Mar;30(1):1-11.

13. Barman N, Haque MA, Uddin MN, Ghosh D, Rahman MW, Islam MT, Rahman MQ, Rob MA, Hossain MA. Status of Serum Zinc in Multidrug Resistant Tuberculosis. Mymensingh medical journal: MMJ. 2016 Jan 1;25(1):27-30.

14. Taneja DP. Observations on serum zinc in patients of pulmonary tuberculosis. Journal of the Indian Medical Association. 1990 Oct 1;88(10):280-1.

15. Kassu A, Mohammad A, Fujimaki Y, Moges F, Elias D, Mekonnen F, Mengistu G, Yamato M, Wondmikun Y, Ota F. Serum IgE levels of tuberculosis patients in a tropical setup with high prevalence of HIV and intestinal parasitoses. Clinical \& Experimental Immunology. 2004 Oct;138(1):122-7.

16. Koyanagi A, Kuffo D, Gresely L, Shenkin A, Cuevas LE. Relationships between serum concentrations of C-reactive protein and micronutrients, in patients with tuberculosis. Annals of Tropical Medicine \& Parasitology. 2004 Jun 1;98(4):391-9.

17. Ciftci TU, Ciftci B, Yis Ö, Guney Y, Bilgihan A, Ogretensoy M. Changes in serum selenium, copper, zinc levels and $\mathrm{Cu} / \mathrm{Zn}$ ratio in patients with pulmonary tuberculosis during therapy. Biological trace element research. 2003 Oct 1;95(1):65-71.

18. Lopes PA, Santos MC, Vicente L, Rodrigues MO, Pavão ML, Neve J, Viegas-Crespo AM. Trace element status ( $\mathrm{Se}, \mathrm{Cu}, \mathrm{Zn}$ ) in healthy Portuguese subjects of Lisbon population. Biological trace element research. 2004 Oct 1;101(1):1-7.

19. Khanna BK, Kumar R, Mukerji PK, Chowdhury AR, Kamboj P. Plasma copper and zinc levels in pulmonary tuberculosis. Ind $\mathbf{J}$ Tub, 1982; 29(3):179-84.

20. Ali W, Ahmad I, Srivastava VK, Prasad R, Kushwaha RA, Saleem M. Serum zinc levels and its association with vitamin A levels among tuberculosis patients. Journal of natural science, biology, and medicine. 2014 Jan;5(1):130. 